\title{
Homens plenos, sem enigmas
}

\section{Fábio Fernandes Villela}

Professor doutor e arquiteto - Departamento de Educação - Unesp, Rio Preto

\section{Resumo}

Este texto tem por objetivo apresentar um feixe de possibilidades das relações entre "educação e trabalho" em Cuba. Trata-se de alguns resultados de nossa pesquisa de pós-doutorado intitulada "A escola da justiça global", onde abordamos os desafios e as possibilidades da educação e trabalho na América Latina. Nesse sentido, partimos da problemática histórico-teórico do tema, formação de "homens plenos" e tematizamos um tipo ideal de homem pleno. Problematizamos especificamente as questões relativas aos intelectuais e a organização trabalho pedagógico nas "escolas no campo" em Cuba (1960-1975). E por fim, abordamos as possibilidades da justiça global na América Latina contemporânea.

Palavras-chave: Educação e Trabalho em Cuba; Escolas no Campo em Cuba (1960-1975); Educação do Campo, Formação de Homens Plenos; América Latina.

\section{Abstract}

This text aims to present a bundle of possibilities of relations between education and labor in Cuba. These are some results of our post-doctoral research entitled "The school of global justice", in which we discussed the challenges and opportunities of education and labor in Latin America. In this sense, we start from the historical and theoretical problems of the topic, formation of multidimensional men and conceptualized an ideal type of multidimensional men. Specifically problematize issues relating to intellectual and pedagogical work in the organization of rural education in Cuba (1960-1975). Finally, we discuss the possibilities of global justice in contemporary Latin America.

Keywords: Education and Labor in Cuba; Rural Education in Cuba (19601975); Rural Education, Multidimensional Men; Latin America.

\section{Resumen}

Este texto tiene como objetivo presentar un conjunto de posibilidades de las relaciones entre la educación y el trabajo en Cuba. Estos son algunos de los resultados de nuestra investigación post-doctoral titulada "La escuela de la justicia global", en la que hablamos de los desafíos y las oportunidades de educación y trabajo en América Latina. En este sentido, partimos de los 
problemas históricos y teóricos del tema, la formación de hombres plenos y conceptualizamos un tipo ideal de hombre pleno. Entonces problematizar cuestiones relacionadas con la organización del trabajo intelectual y pedagógica en las escuelas en el campo en Cuba (1960-1975). Finalmente, se discuten las posibilidades de justicia global en la América Latina contemporánea.

Palabras clave: Educación y Trabajo en Cuba; Las Escuelas en el Campo en Cuba (1960-1975); Educación Rural, Hombres Plenos; América Latina.

\section{1 - Introdução}

dedicado à memória de Roberto Segre (1934-2013).

Este texto tem o objetivo apresentar alguns resultados de nossa pesquisa de pós-doutorado, onde abordamos os desafios e as possibilidades da relação educação e trabalho, através da sistematização das práticas pedagógicas originadas da experiência educacional dos países da América Latina. Esta pesquisa pretendeu aprofundar algumas questões desenvolvidas em nossa dissertação de mestrado, Villela (2003), e em nossa tese de doutorado, Villela (2008). Nesta pesquisa abordamos o trabalho do arquiteto-pedagogo Fernando Salinas (1930-1992), nascido em Havana, Cuba, de um ponto de vista multidisciplinar e especialmente das relações entre "Educação e Trabalho". As respostas às indagações foram dadas a partir de uma análise de "Las Escuelas em el Campo" projetadas e construídas pelos profissionais do Instituto Superior Politécnico "José Antonio Echeverría", La Habana, Cuba (1960-1975), recuperadas através dos relatos de Roberto Segre (2006a), (2006b), (2004), (2000), (1999), (1987), entre outros, da análise da prática pedagógica de Fernando Salinas, através de uma revisão bibliográfica crítica, de pesquisa de campo em Cuba e de entrevistas abertas.

Esta pesquisa de pós-doutorado utilizou a seguinte metodologia e estratégias de desenvolvimento da investigação: (1a) uma revisão bibliográfica crítica realizada: (a) nos textos originais do arquiteto Fernando Salinas presente nas referências bibliográficas. Os textos originais de Fernando Salinas estão reunidos em algumas publicações, a saber, Salinas (1988), Ayala (1992) e Véjar (1994); (b) na revista "Arquitectura / Cuba", da Escola de Arquitetura do Instituto Superior Politécnico "José Antonio Echeverría", La Habana, Cuba, especialmente os números em que o arquiteto Fernando Salinas foi diretor (números 338 até 345, de 1970 a 1976); (c) em livros, teses, artigos, relatórios de pesquisa, revistas especializadas, além de buscas na rede mundial de computadores (internet), especialmente os presentes nas referências bibliográficas, com a finalidade de revisar criticamente a literatura pertinente ao tema produzida no campo relativo à "Educação e Trabalho". Cabe destacar o número da revista Arquitectura / Cuba, número 339 / 1971, Editora CENTSCO, sobre "Las Escuelas en el Campo", foco central de nossa análise teórico-metodológica. A escolha deste exemplar, dentre tantos outros de Arquitectura / Cuba, se deve ao fato de que é dedicado à visão e realização dos planos arquitetônicos e pedagógicos que pretendiam acabar com as diferenças entre o campo e a cidade, o trabalho manual e intelectual, e promover a formação do "homem novo" mediante a educação "integral" dos jovens. Apresenta também o projeto da Cidade Universitária "José Antonio Echeverría" - CUJAE, em La Habana. A revista apresenta seis ensaios acompanhados de fotos e planos: "La escuela revolucionaria como embrión de la comunidad futura"; "Antecedentes históricos de la arquitectura escolar cubana"; "La 


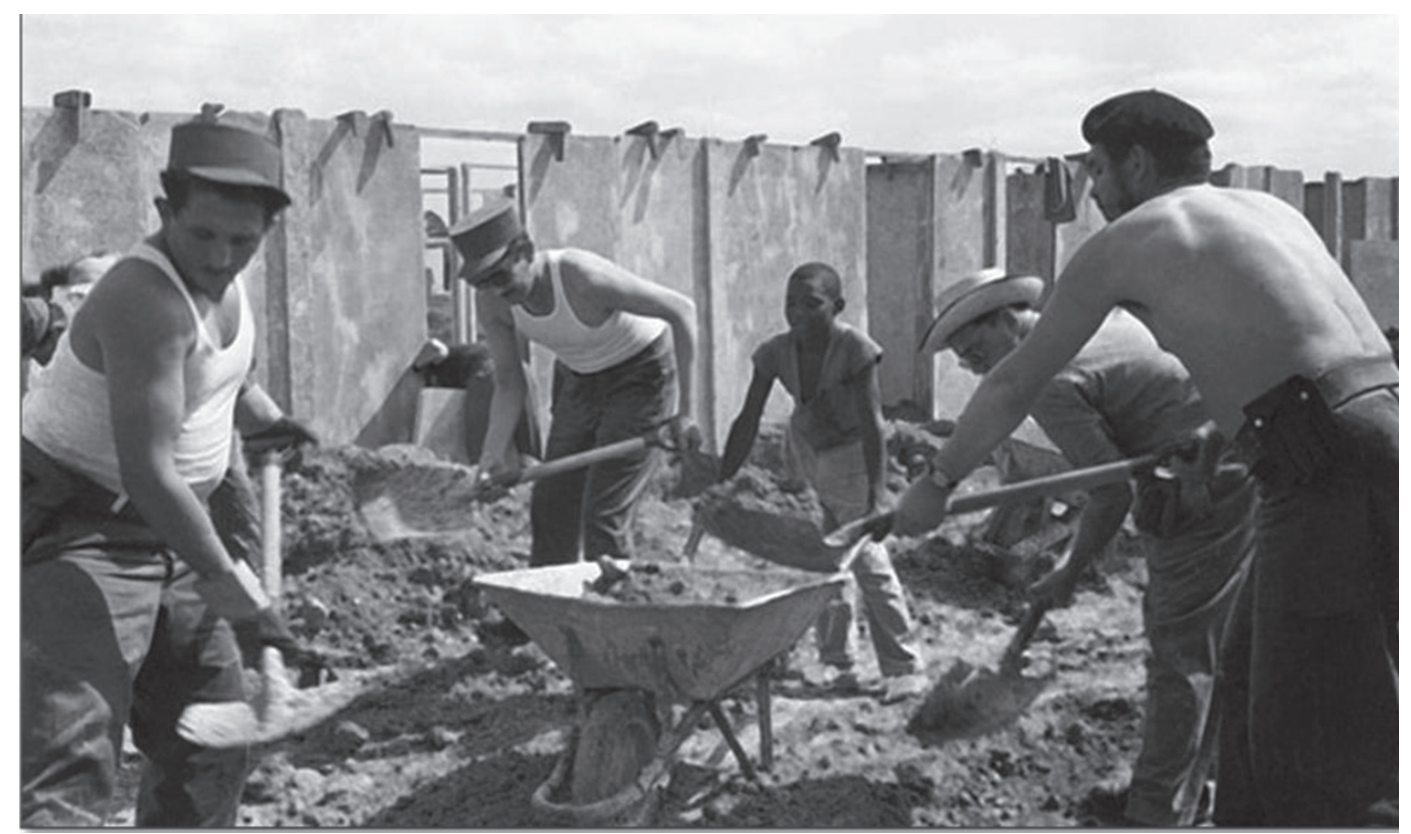

Che no trabalho voluntário, Liborio Noval, Havana, 1961.

Revolución en la educación"; "Tecnologías en las construcciones escolares"; "Ciudad Universitaria "José Antonio Echeverría", La Habana".

Esta pesquisa utilizou ( $\left.2^{a}\right)$ entrevistas abertas, via e-mail e questionários. $\mathrm{O}$ principal entrevistado foi Roberto Segre (FAU-UFRJ), colega e contemporâneo de Fernando Salinas no Instituto Superior Politécnico "José Antonio Echeverría", La Habana, Cuba. Tivemos acesso, através da colaboração de Roberto Segre, a diversos textos de sua autoria, inéditos ou não, sobre o período estudado. Esta pesquisa utilizou (3a) uma pesquisa de campo na cidade de Habana, Cuba, onde foi possível contatar contemporâneos de Fernando Salinas da Escola de Arquitetura do Instituto Superior Politécnico "José Antonio Echeverría", além de pesquisar e atualizar a produção bibliográfica.

\section{2 - A Formação de Homens Plenos}

A formação de homens plenos está presente em diversos trabalhos em Cuba e outros países, especialmente da América Latina Podemos destacar alguns autores que desenvolveram o conceito de "hombres plenos": (Gómez, 2013); (Ramírez, 2009); (Gómez, 2008); (Mendonza, Aguilar, Ramírez, 2008); (Peña, Arias, Silva, 2008); (Tallett et al., 2008); (Bueno, 2006); (Lozano, 2006); (Cano, 2005); (Galindo; Pascual, 2004), (Cormenzana; Gil; Soca, 2003), Segre (1999), (Salinas, 2002, 1988, 1970), Díaz (2002), Kohan (2000), Guevara ([1965] 1979), entre outros. A importância da formação de homens plenos hoje pode ser inferida no seguinte parágrafo, onde os autores afirmam que:

A escola, neste caso, a escola socialista, deve ser o meio ideal para influenciar positivamente os individuos, criando todo um sistema adequado, de todos os pontos de vista, onde exista um ambiente favorável para que se cumpram a instrução e a educação em pé de igualdade; ela deve ensinar a aprender, para que depois se possa colocar essa instrução e educação a serviço da sociedade mediante o trabalho criador do individuo. A escola tem que preparar as novas geraçóes para que atuem como homens plenos. (CORMENZANA; GIL; SOCA, 2003, p. 3). 
O tipo ideal (Cf. Löwy, 1989) ${ }^{1}$ de “hombre pleno” contemporâneo coube a Antonio Guerrero Rodríguez (“Tony Guerrero”), conforme Goméz (2013), escrito por ocasião do lançamento do livro de poemas "Enigmas y otras conversaciones" de Tony Guerrero (RODRÍGUEZ, 2013) 2. Afinal quem é esse tipo ideal de "hombre pleno"? "Tony" nasceu em 16 de outubro de 1958, em Miami, Florida. Em 1959, pouco antes do triunfo da revolução cubana, seus pais decidiram regressar a Cuba e incorporar-se às tarefas do processo revolucionário.

A formação de Tony começa em 1962, ao matricular-se na "Escuela Lazo de la Veja", onde cursa todo primário até 1970. Posteriormente ingressa na "Secundaria Básica José María Heredia", onde cursa o sétimo e oitavo grau. Tony cursa o nono grau na "Escuela Vocacional de Vento”. Em 1973, aos 15 anos, começa seus estudos pré-universitários na "Escuela Vocacional Vladimir Ilich Lenin". Cabe destacar que o projeto dessa escola foi elaborado pelo antigo "Grupo Nacional de Obras Escolares”, começando a ser utilizada em 1970 (ECURED, 2014). Essa escola foi criada especialmente para satisfazer as necessidades de se edificar as "Escuelas Secundarias Básicas en el Campo", conforme veremos a seguir no subitem "3. Os intelectuais e a organização trabalho pedagógico nas 'escolas no campo' em Cuba (1960-1975)”.

Tony foi presidente da Federación de Estudiantes de la Enseñanza Media (FEEM) da região de Boyeros. Em 1974, aos 16 anos, ingressa na Unión de Jóvenes Comunistas de Cuba, ocupando o cargo de secretario organizador do comitê de base. Ao concluir seus estudos pré-universitários, ganha uma bolsa para estudar no Instituto de Aviação de Kiev, Ucrânia, na antiga União Soviética. Em 1983, aos 25 anos, gradua-se em engenharia de construção de aeroportos. Devido a suas qualidades foi treinado em espionagem e contraespionagem, com o consentimento do governo cubano, pelo Comitê de Segurança do Estado (KGB), a principal organização de serviços secretos da antiga União Soviética.

Ao regressar a Cuba, é contratado pela companhia Cubana de Aviación, e começa a trabalhar como especialista na construção de aeroportos, ocupando o cargo de chefe de seção de aeródromos. Tony foi secretário geral do comitê de base e secretário político do comitê da juventude, além de pertencer ao serviço secreto cubano. Em 1989, aos 31 anos, é aceito como membro do Partido Comunista de Cuba. Tony se mantém trabalhando nas tarefas do aeroporto "Antonio Maceo" e sua principal obra foi a ampliação da pista do aeroporto. No ano de 1992, aos 34 anos, Tony muda-se para os Estados Unidos para compor a "Rede Vespa”, uma rede de espionagem cubana aos grupos terroristas anticastristas de Miami.

$\mathrm{Na}$ primeira metade dos anos 90, os grupos terroristas de Miami realizaram 127 operações com o objetivo de afugentar os turistas de Cuba. Os mercenários terroristas, infiltrados entre os turistas, explodiam bombas nos hotéis de Havana e banhistas eram

1 Michael Löwy (1989) utiliza a ferramenta weberiana "tipo ideal" para caracterizar um grupo de intelectuais judeus: Martin Buber, Franz Rozensweig, Walter Benjamin, Gershon Scholem, Franz Kafka, Gustav Landauer, Ernst Bloch, György Lukács, Erich Fromm, entre outros. Ele denominou esses intelectuais de "messiânicolibertários", que se caracterizam por sua dura crítica à sociedade moderna aliada a um retorno muitas vezes difícil à tradição, em busca de reencontro com o encantamento e com a utopia humanista. Utilizamos a mesma ferramenta metodológica para caracterizar os "homens plenos".

2 O livro de poemas “Enigmas y otras conversaciones” de Tony Guerrero (GUERRERO, 2013), "nasceu da amizade e solidariedade. O volume reúne uma ampla e variada gama de linguagens e gêneros para entregar ao leitor uma memória intensa, dura e, no entanto, esperançosa de ações (...)”. O livro reúne "enigmas, poemas, conversações sustentadas a partir da distancia e da proximidade, cartas e crónicas, fotos e obras plásticas" (CENTRO PABLO, 2014). 
alvejados, nas praias cubanas, por tiros de metralhadora disparados de lanchas navegando em alto mar, provenientes de Key West (Flórida, 90 milhas de Cuba). No dia 12 de setembro de 1998 Tony foi detido pelo FBI junto a outros quatro companheiros: Gerardo Hernández Nordero, Fernando González Llort, Ramón Labañino Salazar y René González Sehweret, e julgado em Miami em um processo manipulado, no qual foi condenado à prisão perpetua mais 10 anos de privação de liberdade.

A saga completa dos "Cinco héroes cubanos" pode ser conhecida em detalhes no livro de Fernando Morais: Os últimos soldados da guerra fria: A história dos agentes secretos infiltrados por Cuba em organizações de extrema direita dos Estados Unidos (Morais, 2011). No dia 13 de outubro de 2009, a corte do distrito sul da Florida modificou sua sentença de Tony Guerrero para 21 anos mais 10 meses. A campanha em favor da liberdade dos cinco heróis cubanos, durante esses anos, foi animada por milhares de organizações solidarias em diversas regiões do planeta. Durante os anos de prisão, Tony Guerrero escreveu e publicou diversos livros de poemas e suas pinturas foram expostas em Cuba e outros países.

Em dezembro de 2014, os cinco heróis cubanos cantaram juntos ao trovador Silvio Rodríguez em Cuba. Havia terminado a longa jornada dos antiterroristas. René González havia retornado à ilha em maio de 2013, depois de cumprir 13 anos de cárcere e renunciar a sua cidadania estadunidense; Fernando González regressou em março de 2014, depois de cumprir a pena estipulada. Hernández, Labañino e Guerreiro foram libertados dos cárceres norte-americanos, em virtude de acordos entre os governos de Havana e Washington.

Retomando uma dentre as diversas possibilidades, no sentido de enfeixar uma problemática, a ideia de pesquisar a "formação de homens plenos", surgiu da constatação de que tais experiências possibilitam o desenvolvimento dos estudos sobre uma "pedagogia do trabalho", conferir p. ex., os trabalhos de Rossi, (1982) e Farias (1994). Neste sentido procuramos, em Villela (2009-2010), recuperar a organização do trabalho pedagógico desenvolvido no Instituto Superior Politécnico "José Antonio Echeverría", La Habana, Cuba (1960-1975), (doravante, ISPJAE). Os relatos de Segre (2006a), (2006b), (2004), (2000), (1999), (1987), repõem os acontecimentos políticos, sociais e econômicos que se desencadearam a partir de $1^{\circ}$ de janeiro de 1959 , e que marcaram o rumo do ensino universitário, pelas mudanças de conteúdo imediatas à ação construtiva da Revolução. Segundo o autor, no mês de fevereiro se cria o INAV (Instituto Nacional de Ahorro y Vivienda) que se responsabiliza pela realização de conjuntos habitacionais populares em todo o país, impulsionados por Pastorita Nuñez.

$\mathrm{O}$ arquiteto Osmundo Machado, no Departamento de Proyección Social da Junta Nacional de Planificación (Revolucionaria), elabora um plano para o desenvolvimento de centros comunitários na Sierra Maestra; e o Ministério de Bienestar Social, dirigido por Raquel Pérez, procede à erradicação dos bairros insalubres. Ficava assim, segundo Segre (2000), definida a orientação da arquitetura em função dos planos estatais expostos por Fidel Castro no Colegio Nacional de Arquitectos no inicio desse ano. Conforme relata Segre (2000), a resposta dos profissionais "tradicionais", que concentravam os grandes encargos privados e governamentais, foi a progressiva saída do país em direção aos Estados Unidos. A elaboração sintética do período de 1960 a 1975 foi feita por Segre (2000).

Os principais acontecimentos que o ISPJAE vivenciou na dinâmica da Revolução, são destacados por Segre (2000): (1) as contradições com os Estados Unidos que 
culminaram com o bloqueio de Cuba e cujos momentos dramáticos foram a invasão da Playa Girón (1961) e a Crise de Outubro (1962); (2) a Ofensiva Revolucionária (1968); (3) a Safra dos 10 milhões (1970); (4) a Universalização da Universidade (1968); e (5) o processo de institucionalização do país (1975). Podemos identificar, a partir de Segre (2000), as principais características da organização do trabalho pedagógico no ISPJAE neste período: (a) três correntes básicas da docência; (b) a integração com a dinâmica da Revolução; (c) integração do estudante na problemática da vanguarda cubana; (d) o ateliê vertical; (e) a união entre trabalho e educação; e (f) a formação de homens plenos. Destacamos, a seguir, cada uma destas características.

Conforme relata Segre (2000), seria possível identificar ao longo deste período a existência de três correntes básicas na docência: (1) romântico-individualista de curta duração, encabeçada por Ricardo Porro, que deixou a Escola em 1962, e com um pequeno grupo de adeptos; (2) científico-artístico-cultural, liderada por Fernando Salinas (chefe do Departamento de Desenho) até 1965, e apoiada pelo então diretor, Roberto Carrazana, e um numeroso grupo de professores; e a (3) tecnocrática, apoiada pelo Micons (Ministério da Construção), cujos representantes eram Eduardo Granados, Gonzalo de Quesada e Eduardo Ecenarro, e que ocuparam cargos diretivos na Universidade, entre 1965 e 1969. A seguir, podemos observar alguns projetos de Fernando Salinas.

Outra característica da organização do trabalho pedagógico da escola de arquitetura do ISPJAE é a integração à dinâmica da Revolução. Conforme relata Segre (2000), desde o primeiro plano de estudos formulado em 1960, se assumiu como objetivos essenciais a integração com a dinâmica cultural da Revolução e a participação dos alunos na solução dos problemas concretos que demandava a construção de obras sociais. Segre (2000) sintetiza este princípio com as palavras de Fernando Salinas: "deseja-se a busca de uma arte da Arquitetura dentro das técnicas que determina o desenvolvimento da Revolução" (Cf. Salinas, 1965).

Mais uma característica do trabalho pedagógico, com relação à formação artística, é o abandono de velhos esquemas da formação clássica e integração do estudante na problemática da vanguarda cubana. Segre (2000) revela que a disciplina Plástica cursada no primeiro e segundo ano, teve como docentes: Raúl Martínez, Tomás Oliva, Guido Llinás, Antonia Eiriz y Loló Soldevilla. O curso de Fundamentos da Arquitetura, foi dirigido por Joaquín Rallo, com a participação de Roberto Gottardi, Sergio Baroni y Luis Lápidus, que introduzia o aluno nos conhecimentos objetivos da forma, o espaço e a cor através do estudo da cidade de La Habana e seus edifícios. Segre (2000) informa que haviam construído uma grande maquete da zona histórica, que permitia a identificação e análise de ruas, praças e monumentos.

Uma experiência pedagógica que se difundiu entre as várias escolas de arquitetura da América Latina foi o Ateliê Vertical. Segundo Segre (2000), os ateliês de desenho, dirigidos por Ricardo Porro, Iván Espín, Vittorio Garatti, Fernando Salinas, Raúl Gonzáles Romero e outros, articularam a criatividade com a análise da realidade concreta. Segre (2000) informa que a breve experiência do "Ateliê Vertical" integrava os alunos de todos os anos sob um só professor, e se deslocou para várias cidades do interior, Matanzas, Sancti Spiritus e Trinidad, para familiarizá-los com as diferentes particularidades do território e a sociedade cubana.

A união entre trabalho e educação foi experimentada pelos alunos através do vínculo entre os novos temas urbanos e rurais. Segre (2000) relata que os estudantes 
participaram da construção da Cooperativa "Menelao Mora” na Província de La Habana, sob a direção de Salinas e González Romero, obra que se realizou com habitações camponesas e a participação dos arquitetos Cecilia Menéndez, Selma Díaz, Rafael Moro e Norman Medina. Os alunos e os professores Fernando Salinas e Raúl González Romero, obtiveram dois prêmios internacionais: o da VI Bienal de São Paulo (1961), e no mesmo ano, a Medalha de Prata no 2º Encontro de Faculdades de Escolas de Arquitetura celebrado no México.

A equipe que obteve o prêmio da VI Bienal de São Paulo (1961) propôs o projeto de um centro educacional rural de ensino primário e secundária, situado na Granja del Pueblo "El Corojal", Pinar del Río, e foi desenhado com elementos estruturais pré-fabricados. Junto com Fernando Salinas participaram Rafael Mirabal e os alunos Raquel Cadavid, Norman Medina, Carlos Capote, Alberto Rodríguez, Joel Ballesté, José Cortiñas, Isabel Castillo, Ana Isabel Campaña, Ismael López de Villavicencio, Rogelio Paredes e José Luis Céspedes (Cf. Salinas, 1961). A equipe que obteve a medalha de Plata no México foi dirigida por Raúl González Romero com um projeto de uma cooperativa agrícola no povoado "Pedro Betancourt" de Matanzas.

\section{3 - Os intelectuais e a organização trabalho pedagógico nas "escolas no campo" em Cuba (1960-1975)}

O estreito vínculo entre trabalho e educação pode ser inferido, a partir dos relatos de Segre (2000), na participação dos alunos como desenhistas e projetistas nas oficinas do Micons, responsáveis pelas grandes obras sociais: a Unidad Vecinal de La Habana del Este; a Cidade Universitária José Antonio Echeverría (CUJAE); as Escolas de Arte, as obras turísticas, rurais e industriais. Conforme relata Segre (2000), nos primeiros anos, estudantes e professores trabalhavam nas manhãs no Ministério da Construção e as aulas eram assistidas à tarde até a noite na sede da escola.

O arquiteto Reinaldo Togores [1979 (2009)] participou da experiência coletiva de projeto das "Escolas no Campo" e relata que já em 1959 surge a ideia de criar no principal cenário da guerra revolucionária, a Sierra Maestra, uma Cidade Escolar com capacidade para abrigar 20.000 crianças de origem camponesa, daqueles que, por viver nas zonas montanhosas, haviam sido privados até então do ensino. A Cidade Escolar "Camilo Cienfuegos" foi construída em um local chamado "Las Mercedes", em plena montanha. Contraposta ao isolamento da vivenda camponesa tradicional, se apresenta como um conjunto urbano composto por unidades escolares e habitações, que contando com uma zona cultural/recreativa/administrativa, uma zona de serviços públicos e uma zona industrial de fábricas e granjas modelo para o trabalho dos alunos, ocupando toda uma extensão de 6.700 hectares.

Relatando a experiência das "escolas no campo", Togores (2009), afirma que durante o período de 1969-70 se implantou oficialmente o sistema das "escolas no campo" como meio para vincular o trabalho aos estudantes a partir do sétimo grau e que consistiu em trasladar alunos e professores durante 45 dias a acampamentos habilitados próprios nas zonas de produção agrícola, fazendo possível a participação do estudante nas diversas tarefas produtivas junto aos trabalhadores agrícolas e técnicos do lugar. No curso escolar de 1969-70 iniciou suas atividades a primeira Escola Secundária Básica no Campo. O desenvolvimento deste novo tipo de escola, segundo Togores (2009), "representou um salto qualitativo não só desde o ponto de 


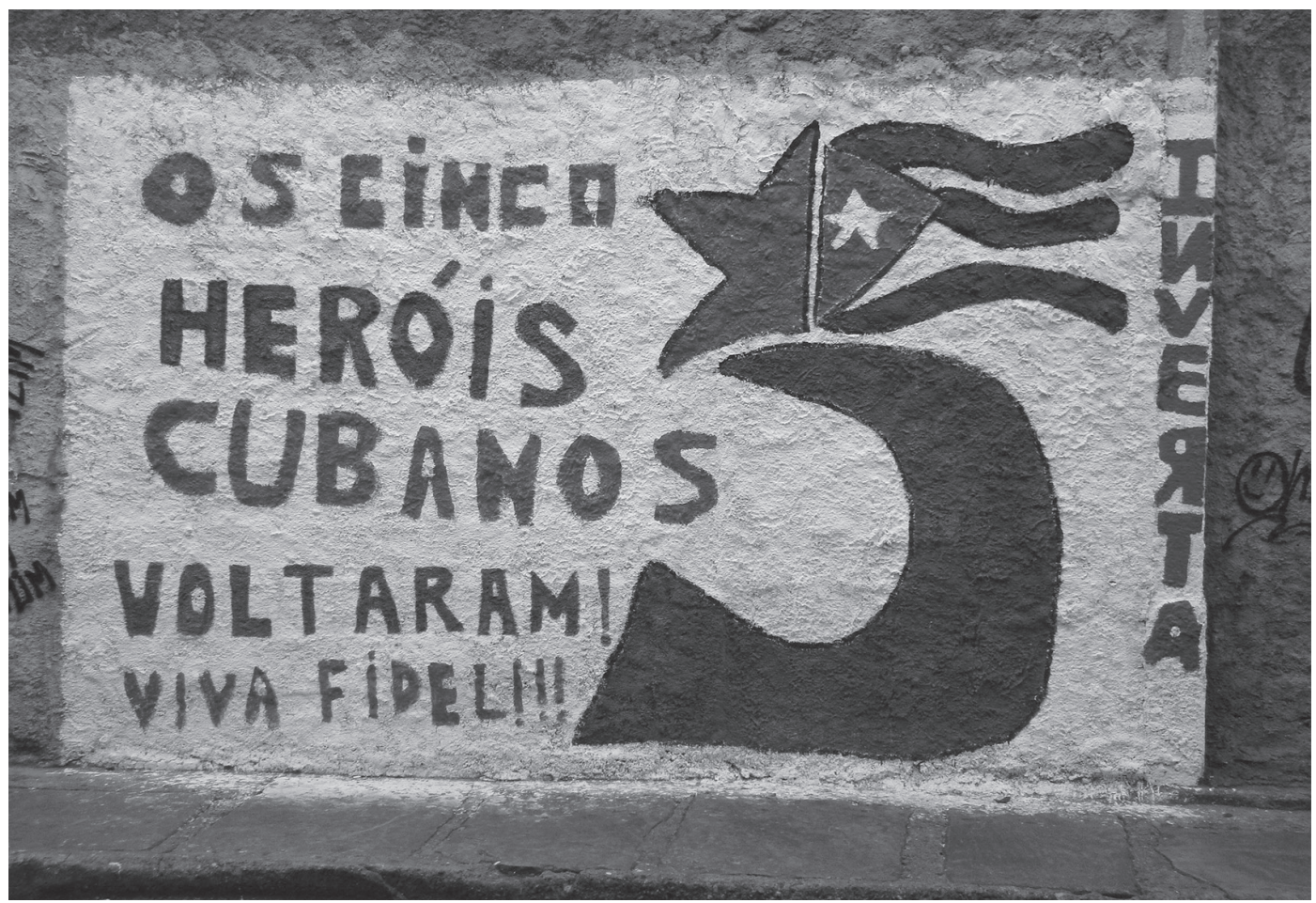

Mural em rua do Rio de Janeiro saudando a volta dos Cinco Heróis.

vista pedagógico: mas também no plano da arquitetura escolar, e repercutiu ainda em outros programas construtivos".

As práticas educativas presentes no projeto das "escolas no campo" em Cuba, segundo Figueroa, Prieto e Gutiérrez (1974, p. 17-29) foram: (1) Educação na coletividade; (2) Combinação de estudo com trabalho; (3) Formação do estudante produtor; (4) Educação universal; (5) União da educação aos planos de desenvolvimento econômico; (6) Educação através do enlace do jovem estudante com o trabalhador do campo; (7) Educação para a formação de habito de trabalho intelectual; (8) Desenvolvimento das inclinações e atitudes individuais; (9) Educação para o estímulo da emulação socialista; (10) Educação para o trabalho de autosserviço e socialmente útil; (11) Educação dos jovens no cuidado e conservação da propriedade social; (12) Educação para a formação vocacional e orientação profissional; (13) Educação para a solidariedade internacional; (14) Educação para a participação dos jovens no governo da instituição escolar; (15) Educação dentro dos princípios do marxismo-leninismo.

Conforme podemos inferir acima, especialmente com relação ao item: “(4) Educação universal”, entre outros, as "escolas no campo" em Cuba possuem "afinidade eletiva” (Cf. Löwy, 1989) com a proposta de "educação no campo" de Bezerra (2010). $\mathrm{O}$ autor afirma que devemos pensar numa "educação no campo" onde não haveria a necessidade de uma educação específica para o campo, dado que os conhecimentos produzidos pela humanidade devem ser disponibilizados para toda a sociedade. Essa proposta é diversa da "educação do campo" de Caldart (2004), entre outros. Para Bezerra (2010),

"Se entendermos que deve haver uma educação específica para o campo, teríamos que considerar as diversidades apontadas acima e perguntarmos, de que especificidade estamos falando? Partindo deste pressuposto, teríamos que considerar a possibilidade de uma educação para os assentados por 
programas de reforma agrária, outra para imigrantes, outra para remanescentes de quilombolas e tantas outras quantas são as diferentes realidades do campo. Nesse caso, trabalhariamos apenas com as diversidades e jamais com o que une todos os trabalbadores, que é o pertencer a uma única classe social, a classe dos desprovidos dos meios de produção e por isso, vendedores de força de trabalho, explorados pelo capital" (BEZERRA, 2010, p. 152).

As informações contemporâneas sobre o fim das "Escolas no Campo" são contraditórias, por um lado fala-se em desativação, por outro, em reparação, remodelação, criação de novas escolas, etc. Rivera (2008) relata que há um amplo movimento de reparação de centros escolares, não só na capital Havana, mas que se estendeu a todo o território nacional com a remodelação de 335 escolas. Também informa que se criaram capacidades e condições para dar merenda escolar aos alunos do ensino médio, e se garantiram as condições necessárias para levar as escolas primárias um professor para cada 20 crianças.

As principais práticas educativas presentes na organização do trabalho pedagógico do ISPJAE, segundo nosso ponto de vista, emergem do debate cultural e ideológico que ocorreu no VII Congresso Internacional da União Internacional dos Arquitetos (UIA) em La Habana (1963). Segundo o relato de Segre (2000), neste congresso participaram milhares de arquitetos e estudantes de todo o mundo onde se trocou ideias e experiências. No debate se explicitou duas tendências antagônicas: a primeira posição defendia o socialismo como um sistema liberador das forças criadoras da sociedade, posição exposta por Che Guevara em "El socialismo y el hombre en Cuba" (Guevara, 2003) e sintetizada na seguinte frase: "nós socialistas somos mais livres porque somos mais plenos; somos mais plenos porque somos mais livres", e a segunda posição que denunciava a ameaça do realismo socialista e do tecnocratismo imposto pelos funcionários, "perigo já assinalado por Fidel”, segundo Segre (2000).

Fernando Salinas foi o relator-geral do VII Congresso da UIA e, segundo Segre (2000), procurou resumir as ideias, que se expressaram em vários discursos e escritos de Castro e Guevara, sobre "o necessário equilíbrio entre a técnica e a estética e a necessidade de colocar o talento criador a serviço das necessidades sociais". Salinas sintetiza o espírito do VII Congresso nas seguintes frases: "a arquitetura é a arte da forma para ser vivida pelo povo" e finalizava sua análise da arquitetura no mundo: "transforme-se ao homem e com ele se transformará a arquitetura" (Guevara, 1964: 3). Essas seriam as principais polêmicas que permeavam o debate cultural e ideológico e que configuraram a organização do trabalho pedagógico nas "escolas no campo" em Cuba de 1960 a 1975.

\section{4 - Conclusões}

Quais os principais desafios da educação e trabalho na América Latina hoje? Segundo nosso ponto de vista, a recuperação de experiências na educação permitiria a comparação e ajudaria a compreender os desafios da formação de crianças e jovens do campo em países que são "grandes sertões", conforme o genial Guimarães Rosa (2001). Esta perspectiva implica em um enfoque coletivo dos problemas para lograr soluções em função de grandes coletivos humanos. A comparação de experiências na educação dos países da América Latina permitiria sistematizar as novas possibilidades de formação omnilateral (Cf. Machado, 2006). 
A recuperação das práticas dos intelectuais orgânicos do ISPJAE contribuiria nesse sentido. A especialista na obra e ex-aluna de Fernando Salinas, Eliana Cárdenas (2002), destaca uma frase que assume um papel chave na perspectiva de formação omnilateral: "[...] transforme-se ao homem e com ele se transformará a arquitetura" (Guevara, 1964). O que transparece na prática educativa de Fernando Salinas e dos intelectuais orgânicos do ISPJAE é a perspectiva guevarista da construção do "homem novo". Guevara afirmava: "A revolução se faz através do homem, mas o homem deve forjar, dia-a-dia, seu espírito revolucionário”, de acordo com Guevara ([1965] 1979, p. 638). Guevara enfatiza o papel central do homem na transição socialista. Para além da transformação da base econômica, Guevara ([1965] 1979: 631), ressalta que: "Para construir o comunismo, simultaneamente com a base material, tem que se fazer o homem novo".

A concepção de "homem novo" salienta o papel central dos homens como sujeitos da transformação histórica, que ao transformarem a si mesmo, transformam a sociedade. A contribuição fundamental desses pedagogos consiste no resgate do horizonte humanista do marxismo. Conforme aponta Löwy (2006, p. 29), os temas centrais da obra marxista de Guevara, a reflexão sobre a transição para o socialismo, a utopia comunista de um homem novo, são temas que tem o seu fundamento no "humanismo revolucionário". Por isso precisamos recuperar, mais do que nunca, esse marxismo humanista, antidogmático, ético, pluralista e revolucionário. Ao analisarmos as práticas educativas dos intelectuais orgânicos do ISPJAE, emerge a temática contemporânea da "justiça global", conforme aponta Garcia (2003, p. 1-2).

Como conclusão, podemos afirmar que os intelectuais orgânicos do ISPJAE, ao colocarem em prática as ideias que estavam in nuce nos textos de Guevara, desenvolveram a temática contemporânea da "justiça global", conforme os trabalhos de Sáez (2009), Monteagudo (2004) e Díaz-Salazar (2003), constituindo uma "escola da justiça global", e fazendo com que suas ideias mantenham sua vigência até os dias de hoje. Os projetos das "escolas no campo" do ISPJAE, especialmente no período de 1960-1975, se propuseram a transformação do universo educacional e sociocultural, em função do desenvolvimento de "homens plenos" e de um elevado compromisso com a comunidade, onde prevaleceu a justiça social e a solidariedade. Essas múltiplas razões fazem com que as ideias desses intelectuais mantenham uma atualidade e uma autenticidade na solução dos desafios da educação de jovens e crianças do campo na América Latina hoje.

\section{Referências}

AYALA Alonso, Enrique (comp.). Fernando Salinas. El compromiso de la arquitectura. México: Universidad Autônoma Metropolitana, Unidad Xochimilco, 1992. BEZERRA NETO, Luiz. Educação do campo ou educação no campo? Revista HISTEDBR On-line, Campinas, n.38, p. 150-168, jun. 2010.

BUENO, Marcia O. G. El trabajo de orientación profesional vocacional hacia carreras pedagógicas en el pre-universitario. Ilustrados Monografias, tesis, bibliografías, educación, Net, Centro Universidad Pedagógica “Raúl Gómez García”, Guantánamo, Cuba, 2006. Disponível em: < http://www.ilustrados.com/tema/8233/Trabajo-Oirentacion-Profesional-Vocacional-hacia-carreras.html >. Acesso em: 26 dez. 2010. 
CANO, Leonor A. La enseñanza integral para el cambio en las universidades latinoamericanas: una visión de la experiencia cubana. Revista Cubana de Educación Superior, Cuba, n. 3, p. 85-102, Mar. 2005.

CÁRDENAS, Eliana. (2002). Por una teoría para transformar el ambiente. Arquitectura y Urbanismo, Vol. XXIII, n. 3, ISPJAE, La Habana, 2002, p. 8-15.

CALDART, Roseli S. Pedagogia do movimento sem terra. São Paulo: Expressão Popular, 2004.

CENTRO PABLO. Apresentação do livro pelo Centro Cultural Pablo de la Torriente Brau. In: RODRÍGUEZ, Antonio G. Enigmas y otras conversaciones. Cuba: Ediciones La Memoria: Centro Cultural Pablo de la Torriente Brau, 2013. (Colección Homenajes). Disponível em: < http://www.centropablo.cult.cu/libros_descargar/ enigmas.htm >. Acesso em: 10 Abr. 2014.

CORMENZANA, Ana J. G.; GIL, Iliana R.; SOCA, Carlos M. Q. El idioma inglés en la formación integral del médico cubano actual. Revista de Ciencias Médicas La Habana, n. 9 (2), p. 1-9, Abr. 2003.

DÍAZ-SALAZAR, Rafael (Org.).Justicia global: las alternativas de los movimientos del Foro de Porto Alegre. 2. ed. Icaria Editorial: Intermón Oxfan, Barcelona, 2003. DÍAZ, Adela H. Una visión contemporánea del proceso de enseñanza aprendizaje. Centro de Estudios para el Perfeccionamiento de la Educación Superior (CEPES), Universidad de La Habana, Net, Cuba, 2002. Disponível em: < http://www.fq.uh.cu >. Acesso em: 26 Dez. 2010.

ECURED. Enciclopedia Cubana en la Red. Escuela Vocacional Vladimir Ilich Lenin. Disponível em: <http://www.ecured.cu/index.php/Escuela_Vocacional_Vladimir_Ilich_Lenin >. Acesso em 10 abr. 2014.

FARIAS, Itamar Mazza de. Pedagogia do trabalho: seus princípios no cotidiano escolar. Campinas: 1994.193p. Tese (Doutorado em Educação). Universidade Estadual de Campinas.

FIGUEROA, Max; PRIETO, Abel; GUTIÉRREZ, Raúl. La escuela secundaria en el campo: una innovación educativa en Cuba. Paris: Unesco, 1974.

GALINDO, Fidel B.; PASCUAL, Yilmy R. La socialización en la formación de una profesión. Dirección Municipal de Educación, Net, Guáimaro, Camagüey, Cuba, 2004. Disponível em: < http://biblioteca.utec.edu.sv/home/ >. Acesso em: 26 dez. 2010. GARCIA, María del C. A. Prólogo. In: GUEVARA, Ernesto C. Justicia global: liberación y socialismo. 1. ed. Buenos Aires: Nuestra America, 2003.

GÓMEZ, Miguel R. Identidad cultural y humanismo en la obra de Leopoldo Zea: significación y actualidad. Poligramas, México, n. 29, p. 335-359, jun. 2008.

GÓMEZ, Ricardo. Hombre pleno, sin enigmas. Tribuna de La Habana, Cuba. Fev. 16, 2013. Disponível em: < http://www.tribuna.co.cu/cinco/2013-02-16/hombre-pleno-sin-enigmas >. Acesso: em: 10 abril 2013.

GUEVARA, Ernesto C. Justicia global: liberación y socialismo. 1. ed. Buenos Aires: Nuestra America, 2003.

.El socialismo y el hombre en Cuba. In: GUEVARA, Ernesto C. Obra revolucionaria. 8. ed. México: Era, [(1965) 1979]. p. 627-639.

. Discurso de clausura del encuentro de profesores y estudiantes. In: Arquitectura Cuba, Cuba: n. 331, La Habana, enero-marzo, 1964, p. 13-14.

KOHAN, Néstor. De Ingenieros al Che. Ensayos sobre el marxismo argentino y latinoamericano. Prólogo de Michel Löwy. Argentina: Editorial Biblos, 2000. 
LOZANO, Gabriel V. El marxismo, hoy. Revista Crítica Jurídica, México, UNAM, n. 26, p. 133-146, Jan. / Dez. 2006.

LOWY, Michael. O pensamento de Che Guevara. São Paulo: Expressão Popular, 2006.

. Redenção e utopia: o judaísmo libertário na Europa central. São Paulo: Companhia das Letras, 1989.

MACHADO, Ilma. F. A criança como sujeito social na educação do campo. In: Educação Pública, Cuiabá, v. 15, n. 27, p. 109-118, jan./abr. 2006.

MENDOZA, Juan C. R.; AGUILAR, Nivia A.; RAMÍREZ, Elio P. La orientación socio-humanística, un aporte a la formación integral del estudiante, Tendencias Pedagógicas, Cuba, n. 13, p. 175-191, Mar. 2008.

MONTEAGUDO, Graciela. Filósofos, caracoles y Letizia: una visita a Chiapas. Net, México, 2004. Disponível em: <http://www.globaljusticecenter.org/articles/ chiapas_esp.htm>. Acesso em 21 dez. 2009.

MORAIS, Fernando. Os últimos soldados da guerra fria: A história dos agentes secretos infiltrados por Cuba em organizações de extrema direita dos Estados Unidos. São Paulo: Companhia das Letras, 2011.

PEÑA, Alberto C.; ARIAS, José M. G.; SILVA, Flor D. R. La interrelación universidad-empresa en la labor educativa profesional. Revista Trimestral de la Facultad de Ingeniería de la Universidad de Holguín, Cuba, Año XIV, n. 2, p. 1-13, Jun. 2008. RAMÍREZ, Elio P. La formación socio humanística del estudiante de arquitectura como campo de reflexión pedagógica. Revista Iberoamericana de Educación, España, Organización de Estados Iberoamericanos para la Educación, la Ciencia y la Cultura (OEI), n. 49/8, p. 1-12, jul. 2009.

RIVERA, Yailin Orta. Una inmensa revolución constructiva. In:Juventud Rebelde. Cuba: Havana, 10 jan. 2008. Nacional, p. 4.

RODRÍGUEZ, Antonio G. Enigmas y otras conversaciones. Cuba: Ediciones La Memoria: Centro Cultural Pablo de la Torriente Brau, 2013. (Colección Homenajes). Disponível em: < http://www.centropablo.cult.cu/libros_descargar/enigmas.htm >. Acesso em: 10 Abr. 2014.

ROSA, João G. Grande sertão: veredas. 20. ed. Rio de Janeiro: Nova Fronteira, 2001. ROSSI, Wagner G. Pedagogia do trabalho 2: caminhos da educação socialista. São Paulo: Moraes, 1982.

SÁENZ, Víctor Manuel Marí. Movimientos sociales y educación popular en tiempos de globalización. Net, Espanha, 2009. Disponível em: <http://www.opech. $\mathrm{cl} /$ educsuperior/alternativas/movimientos_sociales_educacion_popular.pdf $>$.Acesso em: 21 dez. 2009.

SALINAS, Fernando. Una arquitectura para formar al hombre. Boletín de la Escuela de Arquitectura, Volumen XXIII, n. 3, 2002, p. 52-55.

. De la arquitectura y el urbanismo a la cultura ambiental. Guayaquil: Facultad de Arquitectura y Urbanismo, Universidad de Guayaquil, 1988.

. Una educación para el diseño. Boletín de la Escuela de Arquitectura, n. 2, La Habana, julio, 1965 , p. 3.

. Un comentario sobre la presencia de la Escuela de Arquitectura de la Universidad de La Habana en la VI Bienal de Arte de San Pablo, Brasil. In: Espacio, Cuba: n. 1, Año 1, segunda época, La Habana, 1961, p. 22-23. 
. Los espacios del hombre pleno, prólogo: a Roberto Segre. Diez años de arquitectura en Cuba revolucionaria. Cuba: Ediciones Unión, 1970. p. 7-10.

SEGRE, Roberto. Fernando Salinas. In: SADER, Emir; JINKINGS, Ivana; MARTINS, Carlos E.; NÓBILE, Rodrigo (orgs.) Latinoamericana: enciclopédia contemporânea da América Latina e do Caribe. São Paulo: Boitempo, 2006 a.

. A razão construtiva nas escolas paulistas. In: Revista Projeto Design 321. Net, São Paulo, 2006b. Disponível em: <http://arcoweb.com.br/debate/debate96. asp>. Acesso em: 22 dez. 2009.

. Os sonhos da utopia comunista cubana. In: Revista AU, São Paulo: n. 118, p. 53-59, Jan. 2004.

FAU 1960-1975: Los "años de fuego" de la cultura arquitectónica cubana. Net, Roma, Itália, fev./mar, 2000. Disponível em: <http://www.archivocubano.org/fau_1. html>. Acesso em 26 dez. 2000.

. Los espacios del hombre pleno. (1999). Entrevista a Fernando Salinas (1988-1992). Net, Roma, Itália, 1999. Disponível em: <http://www.archivocubano. org/salinas_1.html>. Acesso em 26 dez. 1999.

. Arquitetura da revolução cubana. São Paulo: Nobel, São Paulo, 1987.

TALLETT, Arturo V. et al. El método de enseñanza-aprendizaje en la formación de valores, Revista Médica Electrónica, Cuba, n. 30 (3), p. 1-26, Mar. 2008. Disponível em: < http://www.cpimtz.sld.cu/ > Acesso em:25 maio de 2010.

TOGORES, Reinaldo. 20 años de construcción en Cuba. Obras escolares y sociales. (1979). Net, Espanha, 2009. Disponível em: <http://personales.unican.es/togoresr/ index.html>. Acesso em 21 dez. 2009.

VÉJAR, Pérez-Rubio. Y el perro ladra y la luna enfria. Fernando Salinas: diseño, ambiente y esperanza. México: UAM, UNAM, UIA, 1994.

VILLELA, Fábio F. A escola da justiça global. 2009-2010. Supervisão: Profa ${ }^{\text {. Dra }}$. Liliana Rolfsen Petrilli Segnini. Monografia (Pós-Doutorado). Faculdade de Educação, Universidade Estadual de Campinas.

. Indústria da construção civil e reestruturação produtiva: as novas tecnologias e seus modos de socialização construindo as cidades contemporâneas. São Paulo: Giz Editorial, 2008.

. Rino Levi: hespéria nos trópicos. A racionalização dos processos de trabalho em escritórios de arquitetura e a interação entre intelectuais, estado desenvolvimentista e a industrialização em São Paulo. Campinas: 2003. 324p. Dissertação (Mestrado em Sociologia). Universidade Estadual de Campinas. 